\title{
OS DESAFIOS EDUCACIONAIS EM MEIO À PANDEMIA DA COVID-19: PERCEPÇÕES DE UMA PROFESSORA E PÓS-GRADUANDA NA ÁREA DE LETRAS
}

Patricia Romanisio ${ }^{1}$

O atual cenário da educação brasileira, sobretudo no que diz respeito ao contexto público, reflete a total desigualdade social e emergente necessidade de ampliação do acesso aos meios digitais àgrande parte dos educandos. A dificuldade de acessibilidade à internet não permite o desempenho almejado no âmbito do ensino e aprendizagem. Desse modo, sonhos e projetos educacionais frustrados permearam o ano letivo de 2020.

Atuo como professora efetiva da rede pública, atuo nos anos finais do Ensino Fundamental e também Ensino Médio ministrando disciplinas de Língua Portuguesa e Língua Inglesa. Sou, também, discente do Programa de Mestrado Profissional em Letras (PROFLETRAS/UENP_ Cornélio Procópio - PR -Turma 6), com foco de pesquisa em Literatura Juvenil/poesia.Desta forma, vejo em meu cotidiano a grande dificuldade de aliar o trabalho com a formação profissional, a qual ainda está em andamento. É uma busca deconhecimento por si só, uma vez que a rede pública de ensino não proporciona incentivo algum, tampouco oferece meios facilitadores para cumprir e executar o compromisso de uma formação continuda com maior fundamentação, credibilidade e eficácia no âmbito Stricto Sensu. Neste cenários, é o professor que tem que se desdobrar para cumprir com os compromissos profissionais e acadêmicos, e demais funções que demandam atenção, disposição e amor, como: família, maternidade, afazeres domésticos, tarefas dos filhos, entre tantas outras, como é o meu caso.

Nesse sentido, considerando a perspectiva de formação do profissional de educação para atuar em um cenário remoto e se adequar as demandas tecnológicas atuais e emergenciais, percebouma ampla lacuna efalta de compromisso em relação às políticas públicas para com os educadores em geral. O despreparo na formação do professoratinge de um modo não muito satisfatórioem sua atuação profissional, o que ocasiona, muitas vezes, desmotivação, traumas, medos, entre tantas outras situações que levam esse profissional, até mesmo , ao afastamento da sala de aula.

Além do fato de que a formação profissional está inteiramente ligada à aprendizagem dos educandos, outra premissa é que a maior parte dos educandos que compõem o contexto público de educação em que leciono, são carentes financeiramente, oriundos de famílias desestruturadas, ou

1 Professora Efetiva de Língua Portuguesa e Língua Inglesa - SEED Graduada em Letras - UENP ( 2004) Especialização em Literatura e Estudos da Línguagem - UENP ( 2005) Especialização em Língua Inglesa - UENP ( 2011 ) Especialização em Educação Inclusiva - Barão de Mauá ( 2014) Mestranda PROFLETRAS 2019 (Turma 6) UENP- Campus de Cornélio Procópio- Paraná 
seja, desprovidas de apoio e ouqualquer tipo de incentivo à educação. A falta de recursos básicos é alarmante, quiçá tecnológicos. Uma realidade composta de desafios cotidianos, ocasionando sérias limitações no desenvolvimento educacional é o que se encontra nessa paisagem de pandemia.

No entanto, apesar de tantos obstáculos que dificultam e permeiam esse cenário atual da educação brasileira, não se pode afirmar que o ano foi perdido no âmbito do ensino aprendizagem. As lutas são constantes, afligem tanto alunos como professores e demais profissionais da área pedagógica e também seus respectivos familiares, os quais, neste momento, são participantes ativos no contexto educacional. Pois, o envolvimento familiar favorece a aproximação e vínculo entre instituição e educandos.

Reinventar-se é a palavra chave. O aluno com todas as suas necessidades, teve que se reinventar, seja assistindo a aulas via remota em casa ou emprestando o sinal do $W i$-fi do vizinhoou realizando atividades impressas. O profissional de educação, mesmo sem formação técnica e adequada para atuar com as novas ferramentas tecnológicas, dribla a falta de recursos e tenta com seu próprio esforço promover uma educação efetiva que chegue até o aluno. Ambos se esforçam, no limite de cada um tem um grande aprendizado que jamais será esquecido. A pandemia nos tirou da escola, mas nos ensinou outras formas de aprendizagem.

\section{A abordagem do ensino literário nesse contexto}

Ao considerar a Literatura como elemento de formação e humanização do ser (CANDIDO, 2004), é necessário destacar a importância de sua contribuição para o desenvolvimento pessoal, social e intelectual do aluno, sobretudo, no contexto da Educação Básica. Todorov (2009) destaca o poder que a literatura exerce no indivíduo, quanto à compreensão do mundo que nos cerca e a capacidade de transformar-se em pessoas melhores.

A literatura pode muito. Ela pode nos estender a mão quando estamos profundamente deprimidos, nos tornar ainda mais próximos dos outros seres humanos que nos cercam, nos fazer compreender melhor o mundo e nos ajudar a viver. Não que ela seja, antes de tudo, uma técnica de cuidados para com a alma; porém, revelação do mundo, ela pode também, em seu percurso, nos transformar a cada um de nós a partir de dentro. (2009, p. 76).

Entretanto, desenvolver a leitura literária como ato estético e político e articulá-los aos saberes sistematizados visando a formação de leitores críticos e reflexivos configuram as principais dificuldades educacionais contemporâneas enfrentadas pelo professor de literatura. Uma vez que, a ausência da literatura como componente curricular demonstra, portanto, sua desvalorização no mais 
recente documento norteador da educação brasileira -Base Nacional Comum Curricular(BRASIL, 2017).

Desse modo, a literatura na BNCC aparece apenas como um campo de segmentação do componente Língua Portuguesa. Mais especificamente, ela é abordada no Campo Artístico Literário, sendo referenciada como objeto de manifestação artística e cultural. Nesse sentido, o papel da literatura como formadora e transformadora é substituído e atribuído valor apenas ao leitor fruidor, desconsiderando, assim, todas as suas potencialidades.Ficando, portanto, a literatura, relegada, nesse contexto educacional contemporâneo.

Além das considerações apresentadas, outro aspecto relevante e desafiador para a abordagem literária nesse contexto de pandemia é , como já foi dito anteriormente, a dificuldade de acessibilidade à internet para a grande maioria dos alunos para o acompanhamento das aulas. A Secretaria do Estado e da Educação do Paraná disponibilizou aulas com conteúdos riquíssimos, denominadas Aulas Paraná,de todas as disciplinas via on-line e canal de TV aberto para serem acompanhadas diariamente pelos alunos e professores. Para interação e contato com os alunos, nós professores, utilizamos o Classroom e encontros síncronos pelo Google MEET, além de recados individuais ou em grupos da salas pelo aplicativo do Whatsapp, diariamente. No entanto, apenas metade dos alunos possuem acesso a esse material proporcionado pela SEED, da mesma forma, a falta de participação nos encontros síncronos proporcionados pelos professores regentes da turma foi desmotivadora. Emgeral, apenas três ou no máximo 8 alunos marcam presença nesses encontros. O que faz com que o planejamento das aulas síncronas sejam reelaborados e reorganizados constantemente. Juntando turmas, fazendo um trabalho de divulgação para aulas diferenciadas, chegando até a compartilhar aulas com cidades vizinhas num propósito de integração e interação entre os educandos e toda equipe pedagógica. Ou seja, de acordo com um ditado popular "catando aluno a laço".

As aulas de língua portuguesa e literatura proporcionados pela SEED são compostas de uma gama de gêneros textuais e literários. No entanto, a abordagem literária ainda permanece com espaço reduzido diante dos demais gêneros e/ou conteúdos linguísticos específicos. Diante desse aspecto, cabe ao professor regente, direcionar através de encontros síncronos e atividades impressas ou assíncronas, uma educação literária com maior eficácia. Passeios virtuais a museus, sites de autores, entrevistas, documentários, entre tantas outras ações foram proporcionadas aos alunos. Contudo, apenas uma pequena parcela dos alunos conseguiram ter acesso e se dispuseram a interagir com motivação e grande desempenho nessas aulas mediadas pelo professor via Google Meet.

Percebo que, apesar das dificuldades e limitações que alguns alunos se encontram para prosseguir com os estudos, a falta de motivação e incentivo, mesmo desses que ainda possuem acesso à internet, mas se negam a participar e interagir nas atividades propostas, é assustador. Embora o professor se esforce ao máximopara oportunizar uma proximidade entre aluno e literatura, a dificuldade e receio pela leitura literária ainda permeia a grande maioria dos integrantes do contexto estudantil do 
ensino médio. Acredito que,a falta de abordagem literária significativa nos últimos anos do ensino fundamental reflete o total desinteresse pela leitura nesse cenário. A importância de dar continuidade ao encaminhamento da leitura e à educação literária desde a infância é de total relevância.Desse modo, uma ampla lacuna no âmbito do ensino da leitura literáriaproporciona grandes danos no processo de formação de leitor literato.

Cabe, nesse momento, refletir sobre os aspectos positivos e negativos dos procedimentos metodológicos utilizados nesse período de pandemia. Nesse sentido, as perspectivasde um ensino literário eficaz devem ser conduzidas e planejadas com muito cuidado, pois, a abordagem do letramento literário num cenário remoto, exige do profissional de educação uma formação adequada e efetiva, seja inicial ou continuada, para que a sistematização da leitura e sua compreensão seja desenvolvida plenamente, no intuito de formação de leitores críticos, reflexivos e autônomos.

Resta-nos, enquanto professores, sobretudo, professores de literatura, não desanimar ou retroceder no que diz respeito ao desprestígio e desimportância atribuída ao ensino de literatura, seja nos documentos norteadores ou nos materiais didáticos em que nos embasamos para formar nossos alunos leitores - seja num contexto de pandemia ou não. Sempre buscamos nos qualificar e proporcionar o melhor para nossos alunos. Mesmo que isso nos custe dedicação etempo preciosos.

Entendo que para a plena formação do aluno leitor, apesar das inúmeras dificuldades e limitações que permearam esse período de grande dificuldade no contexto educacional, a importância do professor/leitor é de relevância significativa. O conhecimento em relação à seleção das obras, mercado editorial, resgate de gêneros literários pouco abordados em sala de aula, metodologias efetivas, entre tantas outras abordagens na esfera literária, devem configurar o papel e a formação desse profissional da educação. A fim de que eficientes práticas pedagógicas se concretizem proporcionando um ensino literário fundamentado e eficaz.

Espero que diante de todo esse processo de aprendizagem e dificuldadesque tivemos nesse período de pandemia, sobretudo, em relação às demandas tecnológicas, que possamos nos instrumentalizar e usufruir, nos próximos anos, desses instrumentos inovadores que permearam o ambiente educacional nesse contexto. Embora, não acessível a todos os alunos. Mas, que se possa ter uma acessibilidade aos meios virtuais que abranja a todos discentes. Talvez, em um tempo não muito longe, possamos nos lembrar desse momento em que fomos protagonistas em um cenário caótico, permeado de medos, perdas e dificuldadesextremas. Entretanto, vencedores. Vencedores na saúde, na educação, na proximidade com a família, enfim nas mais variadas formas. Ficarão lembranças apenas. Prioridades foram recolocadas, momentos singelos foram engrandecidos, fizemos parte da história. E estaremos sempre dispostos a aprender e (re)aprender o quanto for possível, e como educadores faremos nosso papel com grande empenho e eficiência e acima de tudo com muito amor. 
Conto

Revista Crioula - $\mathbf{n}^{\circ} \mathbf{2 6}$ - Relações entre literatura e música na produção de língua portuguesa $2^{\circ}$ Semestre 2020 